This item was submitted to Loughborough's Research Repository by the author.

Items in Figshare are protected by copyright, with all rights reserved, unless otherwise indicated.

\title{
A comparison of galvanic skin conductance and skin wettedness as indicators of thermal discomfort during moderate and high metabolic rates
}

PLEASE CITE THE PUBLISHED VERSION

http://dx.doi.org/10.1016/j.jtherbio.2013.09.003

PUBLISHER

(C) Elsevier

VERSION

AM (Accepted Manuscript)

LICENCE

CC BY-NC-ND 4.0

\section{REPOSITORY RECORD}

Gerrett, Nicola, Bernard Redortier, Thomas Voelcker, and George Havenith. 2019. "A Comparison of Galvanic Skin Conductance and Skin Wettedness as Indicators of Thermal Discomfort During Moderate and High Metabolic Rates". figshare. https://hdl.handle.net/2134/13534. 
This item was submitted to Loughborough's Institutional Repository (https://dspace.lboro.ac.uk/) by the author and is made available under the following Creative Commons Licence conditions.

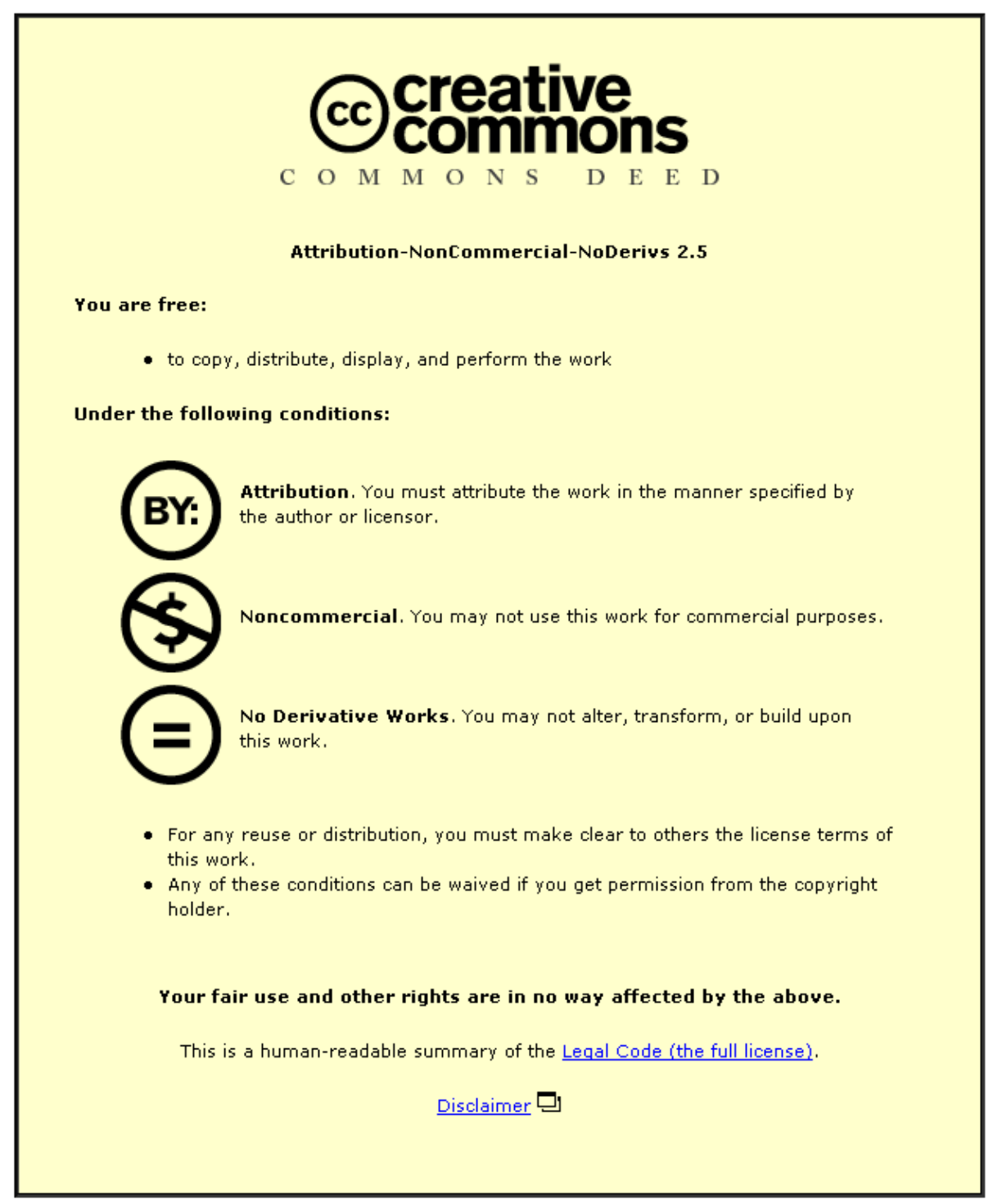

For the full text of this licence, please go to: http://creativecommons.org/licenses/by-nc-nd/2.5/ 
Gerrett, N., Bernard Redortier, Thomas Voelcker, George Havenith, A comparison of galvanic skin conductance and skin wettedness as indicators of thermal discomfort during moderate and high metabolic rates, Journal of Thermal Biology, Volume 38, Issue 8, December 2013, Pages 530-538, ISSN 0306-4565, http://dx.doi.org/10.1016/j.jtherbio.2013.09.003.

\title{
A comparison of galvanic skin conductance and skin wettedness as indicators of thermal discomfort during moderate and high metabolic rates
}

\author{
Nicola Gerrett ${ }^{1,3}$, Bernard Redortier ${ }^{2}$, Thomas Voelcker $^{2}$, and George Havenith ${ }^{1}$ \\ ${ }^{1}$ Environmental Ergonomics Research Centre, Design School, Loughborough University, \\ Loughborough, Leicestershire, LE113TU, UK. \\ ${ }^{2}$ Oxylane Research, Decathlon Campus, Villeneuve d'Ascq, Lille, France. \\ ${ }^{3}$ Institute of Sport and Exercise Science, University of Worcester, Henwick Grove, Worcester, \\ WR26AJ
}

Address for correspondence George Havenith, Loughborough Design School, Environmental Ergonomics Research Centre, Loughborough University, Loughborough, Leicestershire, LE11 3TU. UK.

Phone: $+44(0) 1509223031$

Fax: $+44(0) 1509223014$

Email: G.Havenith@1boro.ac.uk 
Abstract: The relationship between local thermal comfort, local skin wettedness $\left(w_{\text {local }}\right)$ and local galvanic skin conductance (GSC) in 4 body segments during two different exercise intensities was compared in 10 males. In a balanced order, participants walked at $35 \% \mathrm{VO}_{2 \max }$ for 45 minutes (WALK) $\left(29.0 \pm 1.9^{\circ} \mathrm{C}, 29.8 \pm 3.6 \% \mathrm{RH}\right.$, no wind) in one test and in a separate test ran at $70 \% \mathrm{VO}_{2 \max }$ for 45 minutes (RUN) $\left(26.2 \pm 2.1^{\circ} \mathrm{C}, 31.1 \pm 7.0 \% \mathrm{RH}\right.$, no wind). During both tests, participants wore a loose fitting $100 \%$ polyester long sleeve top and trouser ensemble with a low resistance to heat and vapour transfer (total thermal resistance of $0.154 \mathrm{~m}^{2} \cdot \mathrm{K}^{\prime} \cdot \mathrm{W}^{-1}$ and total water vapour resistance of $\left.35.9 \mathrm{~m}^{2} \cdot \mathrm{Pa} \cdot \mathrm{W}^{-1}\right)$. wlocal, change from baseline in GSC $(\Delta \mathrm{GSC})$ and local thermal comfort were recorded every 5 minutes. The results suggest that both $w_{\text {local }}$ and $\Delta \mathrm{GSC}$ are strong predictors of thermal comfort during the WALK when sweat production is low and thermal discomfort minimal $\left(\mathrm{r}^{2}>0.78\right.$ and $\mathrm{r}^{2}>0.71$, respectively). Interestingly, during the RUN $w_{\text {local }}$ plateaued at $\sim 0.6-0.8$ due to the high sweat production, whilst $\triangle \mathrm{GSC}$ gradually increased throughout the experiment. $\triangle \mathrm{GSC}$ had a similar relationship with thermal comfort to $w_{\text {local }}$ during the RUN $\left(\mathrm{r}^{2}>0.95\right.$ and $\mathrm{r}^{2}>0.94$, respectively). Despite the strength of these relationships, the ability of $w_{\text {local }}$ to predict local thermal comfort accurately dramatically reduces in the exponential part of the curve. In a situation of uncompensated heat stress such as high metabolic rate in hot climate, where sweat production is high, $\triangle \mathrm{GSC}$ shows to be a better predictor of local thermal comfort than $w_{\text {local }}$. The $w_{\text {local }}$ data shows regional differences in the threshold which triggers local discomfort during the WALK than RUN; lower values are found for upper arms $(0.22 \pm 0.03$ and $0.28 \pm 0.22)$ and upper legs $(0.22 \pm$ 0.11 and $0.22 \pm 0.10)$, higher values for upper back $(0.30 \pm 0.12$ and $0.36 \pm 0.10)$ and chest $(0.27 \pm 0.10$ and $0.39 \pm 0.32$ ), respectively. However, no regional differences in the threshold of discomfort are found in the $\triangle \mathrm{GSC}$ data. Instead, the data suggests that the degree of discomfort experienced appears to be related to the amount of sweat within and around the skin (as indirectly measured by $\triangle \mathrm{GSC}$ ) at each body site.

Key words: Regional, thermal discomfort, skin wettedness, galvanic skin conductance.

Abbreviations:

$w$; skin wettedness

$w_{\text {local }}$; local skin wettedness

wbody; whole body skin wettedness

GSC; Galvanic skin conductance

$\Delta \mathrm{GSC}$; change from baseline for galvanic skin conductance

\section{Introduction}

Skin wettedness $(w)$ was first introduced by Gagge (1937) and is defined as the ratio between the actual evaporative heat loss and the maximum possible evaporative heat loss for a given environmental condition (Havenith et al. 2002). A closely linked definition is that it represents the fraction of total body surface area covered with sweat. As a dimensionless (nd) variable, it is usually expressed as a decimal fraction, with 1.00 representing the upper limit when sweat covers the entire skin surface and 0.06 representing the minimal value due to insensible perspiration (Nishi and Gagge, 1977). Since its introduction many researchers have reported a strong influence of whole body skin wettedness $\left(w_{b o d y}\right)$ on thermal comfort (Gagge et al. 1969; Nishi and Gagge, 1977; Winslow et al. 1939). More recently, research has investigated regional differences in sensitivity to local skin wettedness $\left(w_{\text {local }}\right)$ using specialised clothing garments comprised of impermeable and permeable 
material to manipulate $w_{\text {local }}$ (Fukazawa and Havenith, 2009; Umbach, 1982). Although this technique is useful for determining regional sensitivity per se, in real conditions the natural distribution of sweat production and skin temperature $\left(T_{s k}\right)$ will be prevalent. Therefore to provide clothing manufacturers information on regional sensitivity to $w$ with ecological validity, it would be more appropriate to assess the natural distribution of physiological and perceptual responses. Lee et al. (2011) recently addressed this and developed a qualitative method based on subjective perceptions to predict locally wet skin in uniform clothing. During a rest-exercise protocol, participants marked areas on a body map that felt wet due to sweat. Areas initially marked were the 'first perceived wetted region' and the most frequently marked regions were named the 'most wetted region'. They found the chest, forehead and upper back were most frequently reported as the first wetted region. These areas are known to produce large volumes of sweat in comparison to other locations (Cotter et al. 1995; Kuno, 1956; Smith and Havenith, 2011, 2012). This contrasts to Fukazawa and Havenith (2009), who through manipulation of $w_{\text {local }}$ in individual body areas determined local humidity sensitivities and found the extremities to have a lower $w_{\text {local }}$ threshold (i.e. more sensitive) than areas of the torso. The methods used may explain the differences observed between the two studies but by combining the quantitative methods of Fukazawa and Havenith (2009) and the ecologically valid methods used by Lee et al. (2011) would be useful in order to determine regional differences in thermal comfort when distribution of $w_{\text {local }}$ is natural.

Fukazawa and Havenith (2009) focused upon the transition from 'comfortable' to 'uncomfortable' and therefore the level of discomfort experienced at their threshold was minimal. Higher levels of thermal discomfort have rarely been explored and neither has its relationship with $w_{\text {local }}$. Doherty and Arens, (1988) noted that the ability to predict $w$ using either the Pierce two-node model or Fanger's comfort equation was significantly reduced at high exercise intensity in comparison to rest, low and moderate exercise intensities. Errors in predicting $w$ will result in inaccurate predictions of thermal discomfort as exercise intensity increases. Interestingly, Lee et al. (2011) reported the diminishing role of $w$ during heavy sweating and claimed that perceived skin wettedness was valid for predicting thermal discomfort during rest or light intensity exercise rather than conditions where sweat production is high. In such conditions $w_{\text {local }}$ is likely to reach ceiling values (1.0). If thermal discomfort worsens, whilst $w$ plateaus, another factor must be influencing thermal discomfort or an alternative measurement is required to aid its prediction.

It has previously been stated that the epidermis swells due to the presence of sweat, which may stimulate the skins tactile mechanoreceptors and contribute towards discomfort (Berglund, 1995; Berglund and Cunningham, 1986). A parameter which monitors the process of sweat production more closely, such as sweat gland activity, skin hydration and surface sweat may have a stronger correlation with perceptual responses than surface sweat measurements alone, as indicated $w_{\text {local }}$. The 
measurement chosen in the present study is galvanic skin conductance (GSC), which reflects the ability of the skin to transmit an electrical current that is enhanced by the presence of sweat (Edelberg, 1972). GSC is associated with the autonomic nervous system due to the activity of sweat glands in the response to emotional and thermoregulatory sweating (Tarchanoff, 1890). Darrow (1964) found an increase in GSC before sweat was present on the skin surface thus reflecting pre-secretory sweat gland activity. It has frequently been used to assess precursor sweat in response to various psychological stimuli (Machado-Moreira et al. 2009) and thermal stimuli (Caldwell et al. 2011). Additionally, Thomas and Korr (1957) found that GSC correlated linearly with increasing and decreasing number of active sweat glands $\left(\mathrm{r}^{2}=0.81\right)$. This was later supported by Fowles (1986) who established that changes in GSC depend upon how much sweat is delivered to the duct and on the number of sweat glands activated. These findings suggest that GSC reflects both intradermal sweat and that on the skin surface in contrast to $w_{\text {local }}$, which only reflects surface sweat. As a result it is hypothesised that GSC may be a better predictor of thermal discomfort during high levels of sweat production and when higher levels of discomfort exist. This is particularly relevant when exercising at higher metabolic rates and/or when exercising in warm-hot conditions where sweat production will be high.

Due to the uncertainties of $w_{\text {local }}$ to predict thermal discomfort at higher metabolic rates and in order to gain a better understanding of the factors that drive thermal discomfort during such conditions, the present study aims to compare the relation between thermal comfort and wlocal and GSC during two different exercise intensities. Due to the reported regional differences in sweat production (Cotter et al. 1995; Kuno, 1956; Smith and Havenith, 2011, 2012) and perceptual responses (Fukazawa and Havenith, 2009; Lee et al. 2011) the regional differences in sensitivity to sweat will also be explored using the two different variables.

\section{Methods}

\subsection{Participants}

Ten British males (height $182.1 \pm 7.5 \mathrm{~cm}$, body mass $74.8 \pm 8.5 \mathrm{~kg}$, age $23.0 \pm 2.8 \mathrm{yrs}, \mathrm{VO}_{2 \max } 52.9 \pm$ $5.2 \mathrm{ml} \cdot \mathrm{kg}^{-1} \cdot \mathrm{min}^{-1}$ ) were recruited from the staff and student population of Loughborough University. The selection criteria included only Caucasian males, aged between 18-45 years to reduce any systemic errors due to ethnic or age-related differences in thermoregulatory responses.

\subsection{Experimental design}

The aim of the investigation was to monitor the physiological responses including $w_{\text {local }}$, skin temperature $\left(T_{\text {sk }}\right)$, core temperature $\left(T_{c}\right)$, body temperature $\left(T_{b}\right)$, GSC and perception of local and whole body thermal comfort. The relationship between local thermal comfort, $w_{\text {local }}$ and GSC was 
investigated during two different conditions specifically designed to produce two different levels of sweat production (i.e. high and low) and discomfort levels. For this purpose, each participant completed a pre-test session to assess fitness level and two main tests on separate days (with a minimum of 1 day separating tests) in a balanced order. The experiment was treated as a repeated measures design.

\subsection{Experimental protocol}

During the first visit, participants' stature and body mass were recorded followed by a submaximal fitness test based on the Åstrand-Rhyming method (ACSM, 2006). The test comprised of four progressive exercise stages on a treadmill $(\mathrm{h} / \mathrm{p} / \cos m o s$ mercury $4.0 \mathrm{~h} / \mathrm{p} / \mathrm{cosmos}$ sports and medical gmbh, Nussdorf, Traunstein, Germany) each lasting 5 minutes. Heart rate (Polar Electro Oy, Kemple, Finland) was recorded during the last minute of each stage. Estimation of $\mathrm{VO}_{2 \max }$ was based upon the linear relationship between heart rate and work rate based upon treadmill speed and angle (Epstein et al. 1987) and data extrapolated to their age predicted heart rate max.

For the main tests, pre and post-test nude mass were recorded. Participants self-inserted a rectal thermistor (Grant Instrument Ltd, Cambridge, UK) $10 \mathrm{~cm}$ beyond the anal sphincter. Eight skin thermistors (Grant Instrument Ltd, Cambridge, UK) were attached to the skin using $3 \mathrm{M}^{\mathrm{TM}}$ Transpore $^{\mathrm{TM}}$ surgical tape, ( $3 \mathrm{M}^{\mathrm{TM}}$ United Kingdom PLC). Eight humidity sensors (MSR electronics $\mathrm{GmbH}$, Switzerland) were fixed to a holder and glued to the skin using Collodion U.S.P (Mavidon Medical Products, USA) to estimate $w_{\text {local }}$. Sensors were located $\sim 2 \mathrm{~mm}$ from the skin at the following locations; chest, abdomen, upper back, lower back, upper arm, lower arm, upper leg and lower leg. Four pairs of pre-gelled electrodes were attached to the chest, upper back, upper arm and thigh for the measurement of GSC using MP35 Biopac Systems (MP35 Biopac Systems, Goleta, California, USA), set to record at $35 \mathrm{~Hz}$. Once equipped participants dressed in a standard clothing ensemble consisting of a $100 \%$ polyester long sleeve top and trouser ensemble with loose fit and a high permeability to favour ventilation, resulting in low resistance to heat and vapour transfer (total thermal resistance of $0.154 \mathrm{~m}^{2} \cdot \mathrm{K} \cdot \mathrm{W}^{-1}$ and total water vapour resistance of $\left.35.9 \mathrm{~m}^{2} \cdot \mathrm{Pa} \cdot \mathrm{W}^{-1}\right)$ tested on a standing thermal manikin (Newton, Measurement Technology Northwest, USA).

Once dressed and fully equipped the participant sat at rest in a thermoneutral environment (mean \pm $\left.\mathrm{SD} ; 19.8 \pm 1.6^{\circ} \mathrm{C}, 40.6 \pm 4.1 \% \mathrm{RH}\right)$ for 15 minutes to allow physiological responses to stabilise. During rest, participants were familiarised with the sensation scales and allowed to practice rating their sensations (see below for details). Following the rest period, participants entered the environmental chamber where they began exercising. For the WALK condition, participants walked for 45 minutes at $35 \% \mathrm{VO}_{2 \max }$ in a chamber at $29.0 \pm 1.9^{\circ} \mathrm{C}, 29.8 \pm 3.6 \% \mathrm{RH}$, with no wind. During 
the RUN, participants walked at $35 \% \mathrm{VO}_{2 \max }$ for 5 minutes, followed immediately by a run at $70 \%$ $\mathrm{VO}_{2 \max }$ for 40 minutes in a chamber at $26.2 \pm 2.1^{\circ} \mathrm{C}, 31.1 \pm 7.0 \% \mathrm{RH}$, with no wind. Participants could drink ad libitum.

\subsection{Measurement and Calculations}

Body mass was measured at the beginning and end of each experimental session as well as fluid intake to determine gross sweat loss (GSL) in grams (g) and grams per surface area (SA) per hour $\left(\mathrm{g} \cdot \mathrm{m}^{2} \cdot \mathrm{h}^{-1}\right)$.

Mean skin temperature and $w_{\text {body }}$ was calculated using the following equation based on eight measurement sites (as used by Umbach, 1982):

$$
\begin{aligned}
& \text { Mean values }=\left(\operatorname{chest}^{* 0.14}\right)+(\text { abdomen*0.08) }+(\text { upper back0.11 })+(\text { lower back*0.11 })+ \\
& (\text { thigh*0.2) }+(\text { calf*0.15) }+(\text { upper arm*0.12) }+(\text { forearm*0.09) }
\end{aligned}
$$

Local skin wettedness is defined as the ratio between the maximum evaporation and the actual evaporation for a given environment (Havenith et al. 2002). It is measured and estimated using the same techniques as described by Fukazawa and Havenith (2009). Local skin wettedness ( $w_{\text {local }}$ ) was measured using humidity sensors as described earlier, which were located $2 \mathrm{~mm}$ from the skin surface. Local skin wettedness ( $w_{\text {local }}$ ) was calculated using the following equation:

$$
w_{\text {local }}=\frac{\left(P_{s k}-P_{a}\right)}{\left(P_{s k, s}-P_{a}\right)}
$$

Where $P_{s k}$ is the water vapour pressure at the skin measured using humidity sensors and was calculated using the following equation:

$$
P_{s k}=\left(\frac{R H}{100}\right) * P_{s k, s}
$$

$P_{s k, s}$ is the saturated water vapour pressure at the skin calculated from skin temperature using the following equation:

$$
P_{s k, s}=e^{\left[23.513-\left(\frac{4030.183}{\left(T_{s k}+235\right)}\right)\right]}
$$


$P_{a}$ is the water vapour pressure of ambient air, which is calculated using the same equations above with ambient values replacing skin values for $\mathrm{RH}$ and temperature. $e$ refers to an exponential function.

In order to reduce errors in the measurement of GSC and compare within and between individuals during both conditions, GSC was standardised as a change from baseline ( $\triangle \mathrm{GSC}$ ) (Wilder, 1962). The baseline value was defined as the lowest GSC value recorded during the 15 minute stabilisation period in a thermoneutral environment. Data from pilot tests confirmed the reduced variation within and between individuals over numerous tests by expressing it as $\Delta \mathrm{GSC}$. Mean $\Delta \mathrm{GSC}$ was averaged over the four sites (chest, upper back, upper arm and upper leg).

All physiological data was measured and recorded continuously (recorded at 10 seconds intervals) during the test with 5-minute averages calculated.

\subsection{Perceptual responses}

Participants rated their thermal comfort on the following 6-point Likert scale with intermediary values; $0=$ comfortable, $-2=$ slightly uncomfortable, $-4=$ uncomfortable, $-6=$ very uncomfortable (modified version based on Gagge et al. 1967). Participants were introduced to the scale and instructed how to interpret and score them. They scored each sensation for their whole body and each local body region (chest, upper back, upper arms, and upper legs) during the last 5 minutes of rest and at 5 minute intervals during exercise. Regional sensitivity to $w_{\text {local }}$ and $\Delta$ GSC was defined by two factors: the threshold of discomfort and the intensity of discomfort experienced. The threshold of discomfort was defined as the $w_{\text {local }}$ and $\triangle$ GSC that corresponds with a comfort vote of -1 . The intensity of discomfort experienced was defined as the highest discomfort vote scored.

\subsection{Data analysis}

Statistical analysis was conducted using Statistical Package (SPSS) version 18.0. Analysis of the main effect of condition, location and time were analysed using three-way repeated measures ANOVA. Post hoc comparisons using Bonferroni correction were performed to analyse individual differences. In some instances, differences between conditions were analysed using Paired samples ttest and corrected for multiple comparisons. Pearson's correlation analysis was performed to assess the relationship between local thermal comfort and each physiological parameter ( $w_{\text {local }}, \Delta \mathrm{GSC}, T_{\text {sk }}$ and $T_{c}$ ). Where data were observed to have non-linear relations (scatterplots), they were first transformed using appropriate transformations to produce an approximate linear relationship and subsequently they were analysed with the standard linear Pearson correlation to assess the relationship. Unless otherwise stated, all measurements are means with standard deviations $( \pm$ S.D) and significance is defined as $\mathrm{p}<0.05$. 


\section{Results}

\subsection{Participants}

Participant 7 was deemed as a 'non responder' as local and whole body thermal comfort was maintained at the same value throughout each test and was subsequently removed from the analysis. All data is expressed without participant 7.

\subsection{Experimental design}

No significant differences were found in $T_{c}$ at rest between the WALK $\left(37.0 \pm 0.3^{\circ} \mathrm{C}\right)$ and RUN $(37.1$ $\left.\pm 0.3^{\circ} \mathrm{C}\right)(\mathrm{p}>0.05)$. However, the increase in $T_{c}$ from baseline to the end of the experiment was significantly less for the WALK $\left(37.2 \pm 0.3^{\circ} \mathrm{C}\right)$ than the RUN $\left(38.1 \pm 0.4^{\circ} \mathrm{C}, \mathrm{p}<0.001\right)$. Alongside this, GSL was significantly higher at the end of RUN compared to the WALK $(516.7 \pm 132.8$ and $271.5 \pm 90.5 \mathrm{~g} \cdot \mathrm{m}^{-2} \cdot \mathrm{hr}^{-1}$, respectively, $\left.\mathrm{p}<0.001\right)$.

Table 1 lists the mean $( \pm \mathrm{SD})$ values at the end of each condition (WALK and RUN) for $w_{\text {local }}, \Delta \mathrm{GSC}$ and local $T_{s k}$. According to three way repeated measures ANOVA, there was a significant effect of condition on $w_{\text {local }}$ and $\Delta \mathrm{GSC}(\mathrm{p}<0.05)$ but not for local $T_{s k}$ as it was similar between conditions. A significant effect of time was found on all three parameters as they increased from rest to the end of exercise. No significant effect of location was observed for $\Delta$ GSC. A significant effect of location was found for $w_{\text {local }}$ and pairwise comparison revealed that the upper back was significantly higher than all other locations and the upper legs were significantly lower than all locations $(\mathrm{p}<0.05)$ The chest was also significantly higher than the upper arms $(p<0.05)$. A significant effect of location $(p<0.001)$ was observed for local $T_{s k}$ and pairwise comparison revealed the upper legs were significantly cooler than the chest and upper back $(\mathrm{p}<0.05)$.

\subsection{The relationship between thermal comfort, $w_{\text {local }}$ and $\Delta$ GSC}

Figure 1 and Figure 2 illustrate the relationships between local thermal comfort and $w_{\text {local }}$ and $\Delta \mathrm{GSC}$ (respectively) during both conditions. The strength of the relationships $\left(\mathrm{r}^{2}\right)$ between thermal comfort and each variable are displayed in Table 2. In Figure 1, during the WALK, a strong linear relationship exists between local thermal comfort and $w_{\text {local }}\left(\mathrm{r}^{2}>0.78, \mathrm{p}<0.001\right)$. However, during the RUN, local thermal comfort has an exponential relationship with $w_{\text {local }}$ and therefore was transformed (using an exponential function) for further analysis and the result indicated strong significant relationships $\left(r^{2}>0.94, p<0.001\right)$. The relationship between thermal comfort and $\Delta G S C$ was curvilinear for both conditions (Figure 2) and was transformed (square root) prior to analysis. The strength of these relationships improves from the WALK $\left(\mathrm{r}^{2}>0.71, \mathrm{p}<0.001\right)$ to the RUN $\left(\mathrm{r}^{2}>0.95, \mathrm{p}<0.001\right)$ at each location. Local thermal comfort did not consistently have good relationships with local $T_{s k}$ and where relationships did exist they were significant and linear $\left(r^{2}=0.37\right.$ to $\left.0.96, p<0.05\right)$. Local thermal 
comfort had a strong relationship with $T_{c}$ which was strengthened during the RUN in comparison to the WALK $\left(\mathrm{r}^{2}=0.82\right.$ and $\mathrm{r}^{2}=0.50$, respectively, $\left.\mathrm{p}<0.05\right)$.

\subsection{Regional sensitivity to $w_{\text {local }}$ and $\Delta$ GSC.}

Local and whole body threshold of discomfort according to $w_{\text {local }}$ and $\Delta \mathrm{GSC}$ are displayed in Table 3. The threshold of discomfort are defined as the point at which participants no longer feel comfortable (-1 vote). The values in Table 3 are the mean of each individual's $w_{\text {local }}$ and $\Delta$ GSC value at the threshold. Two-way repeated measures ANOVA revealed no significant effect of condition for $w_{\text {local }}$. $(\mathrm{p}>0.05))$. A significant effect of location is observed for $w_{\text {local }}$ but not for $\Delta \mathrm{GSC}$. Pairwise comparison with Bonferroni correction revealed no significant differences between locations for $w_{\text {local }}$. Without Bonferroni corrections the upper back was significantly less sensitive than all other locations and the chest was significantly less sensitive than the upper legs. According to Table 3, threshold of discomfort for $w_{\text {local }}$ indicate that the upper legs and upper arms are the most sensitive during the WALK due to the lower $w_{\text {local }}$ values $(0.22 \pm 0.11$ and $0.22 \pm 0.03$, respectively). The upper back is classed as the least sensitive as it requires a higher $w_{\text {local }}$ values before participants no longer felt comfortable $(0.30 \pm 0.12)$. During the RUN the threshold of discomfort for $w_{\text {local }}$ occur at higher values than the WALK but suggest a similar order of sensitivity, with the extremities being more sensitive than the torso areas. If the same principle is applied to $\triangle \mathrm{GSC}$ then the upper back and upper arm are the most sensitive and the upper legs the least sensitive.

The intensity of discomfort (i.e. the highest discomfort score reported) and the corresponding $w_{\text {local }}$ reached varied between locations, these are listed in Table 4. Two-way repeated measures ANOVA revealed a significant effect of condition for $w_{\text {local }}, \triangle \mathrm{GSC}$ and thermal comfort as all locations were significantly higher during the RUN compared to the WALK $(\mathrm{p}<0.05)$. A significant effect of location was observed for thermal comfort, with the whole body (3.3) and chest (3.1) scoring significantly higher discomfort votes than the upper legs (2.4). A significant effect of location was observed for $w_{\text {local }}$ and pairwise comparison showed significant differences between all locations except the whole body and the upper arm, the chest and the upper back ( $>0.05$ ). No significant effect of location was observed for $\triangle \mathrm{GSC}$.

During the WALK the chest and upper back scored the highest vote (>-2.0), followed closely by the upper arm $(-1.9 \pm 1.3)$ whilst the upper legs scored the lowest discomfort score $(-1.7 \pm 1.1)$. The discomfort scores appear to be relative to $w_{\text {local }}$ as the chest and upper back also had the highest $w_{\text {local }}$ $\left(0.57 \pm 0.19\right.$ and $0.65 \pm 0.21$, respectively) and the upper legs have the lowest $w_{\text {local }}(0.32 \pm 0.03)$. However, the exception appears to be the upper arm which also had a high discomfort score, similar to the lower back $(-1.9)$ yet a low $w_{\text {local }}(0.37 \pm 0.14)$. This response was mirrored by the $\Delta$ GSC data as the highest discomfort scored corresponded with the highest $\triangle \mathrm{GSC}$ values, except the arms. During 
the RUN, a similar response to the WALK occurred, with the highest discomfort scores corresponding with the highest $w_{\text {local }}$ and $\Delta \mathrm{GSC}$.

\section{Discussion}

\subsection{A comparison of $w_{\text {local }}$ and $\triangle G S C$ in predicting thermal discomfort during different exercise intensities}

Past research has established the relationship between whole body thermal comfort and $w_{\text {body }}$ and 0.30 has been defined as the threshold of discomfort at rest (Gagge et al. 1969; Nishi and Gagge, 1977; Winslow et al. 1939). Research has moved forward by identifying regional differences in thermal comfort to $w_{\text {local }}$ (Fukazawa and Havenith, 2009; Umbach, 1982). However, the research has mainly focused upon the threshold of discomfort for $w$ and since its introduction by Gagge (1937) researchers have confirmed the diminishing role of $w$ during heavy sweating on the prediction of thermal discomfort (Doherty and Arens, 1988; Lee, et al. 2011). As a result, this study aimed to address the relationship between thermal discomfort and $w$ and introduce $\Delta \mathrm{GSC}$ that could improve and/or aid the prediction of thermal discomfort during high levels of sweat production as found in exercise.

Table 2 indicates the strength of the relationship between thermal comfort and $w_{\text {local }}$ and $\Delta \mathrm{GSC}$, respectively. The results indicated a strong linear relationship between local thermal comfort and $w_{\text {local }}$ during the WALK at all locations $\left(\mathrm{r}^{2}>0.78\right.$ to 0.98$)$. During the RUN, $w_{\text {local }}$ increased and tended to plateau at values $>0.60$, during which thermal discomfort however continued to increase. As such, an exponential relationship is observed between the two variables. Using the data in the present study to predict thermal discomfort at higher metabolic rates requires the data to be transformed, which is useful in terms of analysis but poses several issues when interpreting the findings. During high sweat production, $w_{\text {local }}$ will reach ceiling values and the sensitivity of $w_{\text {local }}$ to predict thermal comfort beyond a moderately uncomfortable state diminishes. As a result the uncertainty in predicting thermal discomfort will increase dramatically in the exponential part of the curve. Here, a small change in $w_{\text {local }}$ leads to a big change in comfort. Any variations or uncertainty in $w_{\text {local }}$ will thus result in large errors in the prediction of local thermal discomfort. Lee et al. (2011) claimed that predicting comfort was more difficult at higher $w$, which is supported by the findings of this study.

The plateau in $w_{\text {local }}$ at values $>0.60$ and the concomitant increase in thermal discomfort suggests either another factor must be driving discomfort or there are errors with the measurement. The measurement of $w_{\text {local }}$ in the present study was achieved using humidity sensors located in the microclimate, approximately $2 \mathrm{~mm}$ from the skin. Even though this is relatively close, the distance between the humidity sensor and the skin may not be sufficient to provide a true representation of surface $w_{\text {local }}$ at higher sweat rates. If the skin is fully saturated with sweat then it should have reached 
a maximum value of 1.0, yet in some cases the skin visually appeared to be completely saturated, but $w_{\text {local }}$ did not exceed $0.85 \pm 0.09$. It is plausible that a measurement artefact may contribute to the underestimation of $w_{\text {local }}$ but the plateau is a true representation of the surface being saturated with sweat, illustrating the issues associated with the measurement of $w_{\text {local }}$ as used in the present study and by others (Fukazawa \& Havenith, 2009; Umbach, 1982).

The classic work of Gagge et al. (1967) demonstrated the diminishing role of $T_{s k}$ on thermal sensation as it rises above $33^{\circ} \mathrm{C}$. It is proposed that sweating maintains $T_{s k}$ at a favourable level and thus thermal sensation does not increase but discomfort will. This continual increase in thermal discomfort was found to correlate with $w$. In the present study, $T_{s k}$ demonstrated moderate-strong relationship with thermal comfort, which actually improved from the WALK to the RUN despite a significantly higher GSL. Although this does not support the findings of Gagge et al. (1967), Thermal comfort had a stronger relationship with $\triangle \mathrm{GSC}$ than $T_{s k}$.

Another factor that may contribute towards an increased thermal discomfort at high metabolic rates is $T_{c}$. An increase in sweat production typical occurs concomitantly with an increase in $T_{c}$ so with heat exposure and/or with exercise higher thermal discomfort votes will likely be influenced by both. Stronger relationships were observed between local thermal discomfort and $\Delta \mathrm{GSC}\left(\mathrm{r}^{2}>0.71\right)$ than $T_{c}$ $\left(r^{2}>0.50\right)$. The relationship between thermal discomfort and $\Delta \mathrm{GSC}$ strengthened as metabolic rate increased (WALK; $\mathrm{r}^{2}>0.71$ and RUN; $\mathrm{r}^{2}>0.95$ ). GSC has been reported to represent pre secretory sweat gland activity (Caldwell et al. 2011; Darrow, 1964; Machado-Moreira et al. 2009), the number of active sweat glands (Thomas and Korr, 1957) and the amount of sweat produced (Fowles, 1986). Therefore it indicates not only what is happening on the skin surface but also within the epidermis where the receptors are located, which may explain why it is a good predictor of thermal comfort. . However the number of potential measurement errors both systematic and unsystematic with GSC is high. Considerable pilot testing took place to reduce possible errors during testing. Reliability was assessed during pilot tests and whilst some variations did exist the response to a given condition was similar. The large variation in individual sweat gland output may accounts for the variation seen in GSC but also in that from other studies when measuring sweat (Smith \& Havenith, 2011, 2012; Cotter et al. 1995; Machado-Moreira et al. 2008). Standardising the value relative to a baseline value aimed to reduce these errors but the high dispersion of values reduces the certainty of predicting thermal discomfort using GSC as can be seen in Table 3 and 4. As a result more research is required to understand the extent to which GSC is influenced by sweat gland activity, epidermal hydration and surface sweat. However, the reduced strength of the relationship between thermal comfort and surface sweat (as indicated by $w_{\text {local }}$ ) and the increasing relationship between thermal comfort and $\triangle \mathrm{GSC}$ at higher sweat levels suggests that an internal component in the skin could be a strong contributing driver for discomfort. Discomfort may be related to the accumulation of sweat in the skin, on the skin 
and within the clothing layer next to the skin. During sweat production the skin swells, becomes soft and enhances the sensitivity of receptors (Berglund and Cunningham, 1986). Gwosdow et al. (1986) noted an increase in the friction between skin and clothing as well increased perceived fabric coarseness with increasing moisture content in the skin. This aspect seems to be better represented by $\Delta \mathrm{GSC}$ than by the surface skin wettedness ( $\left.w_{\text {local }}\right)$. The perception of thermal comfort may not be a solely thermal response but multiple factors relating to the perception of temperature and moisture, in which the skin-fabric interaction may play a large role. Potentially the hydration of the skin due to the production of sweat has an influential role on perceptual responses but further research is required to address this.

Collectively the comparative relationships between thermal comfort, $\Delta \mathrm{GSC}$ and $w_{\text {local }}$ and the issues surrounding the methods of measuring $w_{\text {local }}$ suggest it is not the sweating per se that cannot predict thermal discomfort during high sweat rates but $w_{\text {local }}$ as a parameter on its own. Doherty and Arens (1988) stated that models which use $w$ to predict thermal discomfort become less accurate for high intensity exercise than at rest or during low-moderate intensity exercise. This also conforms to the findings from Lee et al. (2011).

\subsection{Regional differences in local thermal discomfort sensitivity}

To the authors knowledge only Fukazawa and Havenith (2009) and Umbach (1982) have investigated regional sensitivity to thermal discomfort using $w_{\text {local }}$ as a predictor. The methods used to determine sensitivity is based on the thresholds for discomfort or the transition away from comfortable and noting the corresponding $w_{\text {local }}$. The application of such methodologies will be discussed here.

In the present study, the threshold for discomfort was defined as the point at which the participants no longer felt comfortable ( -1 vote). These were determined for both $w_{\text {local }}$ and $\Delta \mathrm{GSC}$ and values are displayed in Table 3. During the WALK, local threshold for discomfort suggests that the upper arms and upper legs are the most sensitive areas, due to the lower $w_{\text {local }}$ required to no longer feel comfortable. The upper back was a significantly less sensitive area than all other location across the body. The threshold for discomfort using $\triangle \mathrm{GSC}$ provide less informative data due to the small variations in values in comparison to the range of $\triangle \mathrm{GSC}$ achieved and thus the significance of the differences between the comfort limits are questionable. In addition, Figure 2 suggests the slope of the line between local thermal comfort and local $\Delta$ GSC suggest that there is not much difference between regions in intrinsic sensitivity to moisture. The intensity of discomfort experienced maybe a more useful measurement as it may indicate the areas that are more sensitive to efferent inputs such as sweat and drive thermal discomfort to higher levels. This is particularly true of the upper legs, which according to $w_{\text {local }}$ are very sensitive areas due to a lower comfort limit and were significantly lower than the chest and upper back, , yet the legs scored the lowest discomfort scores at the end of the RUN 
$(-3.1 \pm 1.76)$. The chest and upper back had higher discomfort scores alongside higher $w_{\text {local }}$ and $\Delta \mathrm{GSC}$ at the end of exercise. This supports findings from Lee et al. (2011) who noted that the areas perceived as the wettest regions were the upper back, chest, front and back neck and forehead whilst the palms, feet and dorsal hands were the least wet regions. These areas, according to Smith and Havenith $(2011,2012)$ are areas of high and low sweat production, respectively. Perhaps areas which score the highest discomfort votes can be deemed as critical areas, in the sense they are the most exposed to discomfort as a combination of their intrinsic sensitivity to sweat and the sweat effectively present (related to local sweat rate).

Past researchers have used $w$ to predict the threshold of discomfort and therefore restricted the methodology to low $w_{\text {local }}$ and discomfort scores (Fukazawa and Havenith, 2009; Umbach, 1982). To the author's knowledge this is the first experiment to compare thermal comfort over different exercise intensities and the results suggest that higher discomfort scores are relative to the amount of sweat produced and accumulated around the skin as indirectly measured by $\triangle$ GSC. In this case the areas of the torso should be of primary concern when designing clothing to promote thermoregulation and thermal comfort.

The present study aimed to investigate regional differences in thermal comfort sensitivity to the presence of sweat using $w_{\text {local }}$ and GSC. Whilst application using the threshold of discomfort to determine regional sensitivity have just been questioned an interesting issues arises when comparing the findings between our study and that of Fukazawa and Havenith (2009) and Umbach (1982). Though the pattern of sensitivity across the body appears to be similar between all threes studies, the values for the thermal comfort limits were much lower in the present study. This is likely due to the fact that in both studies they manipulated $w_{\text {local }}$ to increase independently of others zones. This enabled them to identify the 'true' threshold of discomfort for individual body sites. Whilst mechanistic research is informative it is not representative of real life situations whereby sweat will be produced across the body at different rates (Smith and Havenith, 2011, 2012), therefore more ecologically valid studies are required. Higher $w_{\text {local }}$ values for the thresholds of discomfort were found by Fukazawa and Havenith (2009) and Umbach (1982), suggesting that more sweat is required locally to influence thermal comfort when $w_{\text {local }}$ is not naturally distributed. In the present study all physiological responses increased simultaneously and any changes in local thermal comfort may be attributed to other local or whole body changes. The interaction between body segments and the influence on local and whole body perceptual responses has been investigated by Arens and Zhang (2006) and they found that the overall perceptions are dominated by the one or two most unfavourable local perceptions. Their research focused upon regional differences in skin temperature in uniform conditions. Further research is required to understand the interaction between local and whole body sweat production on thermal comfort. The interactions between local and whole thermal comfort may 
explain the lower thresholds for discomfort observed in the present study compared to Fukazawa and Havenith (2009) and Umbach (1982) but this requires further comparative research using the same perceptual scales.

\section{Conclusions}

The natural variation of physiological responses $\left(\Delta \mathrm{GSC}, w_{\text {local }}\right.$ and $\left.T_{s k}\right)$ and thermal comfort were measured in male participants and the relationships analysed. The results revealed that during high levels of sweat production $w$ plateaued at approximately $0.60-0.85$, depending on condition, suggesting either a maximum value has been reached or a measurement artefact exists with $w_{\text {local }}$ This resulted in an exponential relationship between thermal comfort and $w_{\text {local }}$ which reduces the latter's ability to accurately predict the intensity of thermal discomfort experienced when sweat production is high. The findings revealed that thermal comfort has a stronger relationship with $\Delta G S C$, especially at higher metabolic rates when sweat production is greater. This supports the hypothesis that thermal discomfort may be more related to the amount of moisture present within the skin and on and around the skin itself, as reflected by $\Delta \mathrm{GSC}$, rather than just a proportion of wetted area at skin surface as indicated by $w_{\text {local }}$.

Acknowledgements: The authors would like to acknowledge the continued support from Oxylane group during this study, with special thanks to Sophie Herpin.

Role of the funding body: The present research was done in the context of an industry- co-funded $\mathrm{PhD}$. Bernard Redortier, member of the sponsoring industry (Oxylane Research), contributed to the conception and design of the experiment and contributed to the paper write-up.

\section{References}

American College of Sport Medicine. 2005. ACSM's guidelines for exercise testing and prescription. Seventh ed. Lippincott Williams \& Wilkins.

Berglund, L.G. 1995. Comfort criteria - humidity and standards, Proceedings of the Pan Pacific symposium on Buildings and Urban Environmental Conditioning in Asia, p. 369.

Berglund, L.G., Cunningham, D.J. 1986. Parameters of Human Discomfort in Warm environments. ASHRAE Trans. 92.

Caldwell, J.N., Nykvist, A., Powers, N., Notley, S., Lee, D., Peoples, G. \& Taylor, N. 2011. An investigation of forearm vasomotor and sudomotor thresholds during passive heating, following whole body cooling. XIV International Conferences of Environmental Ergonomics, Paschalidis Medical Publisher, Nafplio, p. 29.

Candas, V., Libert, J.P., Vogt, J.J., 1979a. Human skin wettedness and evaporative efficiency of sweating. Appl. Physiol. 46, 3, 522-528. 
Candas, V., Libert, J.P., Vogt, J.J. 1979b. Influence of air velocity and heat acclimation on human skin wettedness and sweating efficiency. J. App. Physiol. 47, 6, 1194-1200.

Cotter, J.D., Patterson, M.J., Taylor, N.A.S., 1995. The topography of eccrine sweating in humans during exercise. Eur. J. App. Physiol. 71, 6, 549-554.

Darrow, C.W. 1964. The rationale for treating the change in galvanic skin response as a change in conductance. Psychophysiology, 1, 1, 31-38.

Doherty, T. J., and E. A. Arens, 1988. Evaluation of the physiological bases of thermal comfort models. ASHRAE Trans. 94, 1, 15.

Edelberg, R. 1972. Electrical activity of the skin: Its measurements and uses in psychophysiology. In: Greenfield, N.S. \& Sternbach, R.A. (eds.) Handbook of Psychophysiology. New York, USA: Holt, Rinchart \& Winston, pp. 367-418.

Epstein, Y., Stroschein, L., Pandolf, K. 1987. Predicting metabolic cost of running with and without backpack loads. Eur. J. Appl. Physiol. Occup. Physiol. 56, 5, 495-500.

Fowles, D.C. 1986. The eccrine system and electrodermal activity, in: Coles, M.G.H. Donchin, E., Porges, S.W. (Eds.), Psychophysiology. New York, USA: Guilford Press, pp. 51-96.

Fukazawa, T., Havenith, G. 2009. Differences in comfort perception in relation to local and whole body skin wettedness. Eur. J. App. Physiol. 106, 1, 15-24.

Gagge, A.P., Stolwijk, J.A., Nishi, T. 1969a. The prediction of thermal comfort when thermal equilibrium is maintained by sweating. ASHRAE Trans. 75, 2, 108-121.

Havenith, G., Holmér, I., Parsons, K. 2002. Personal factors in thermal comfort assessment: clothing properties and metabolic heat production. Energ. Buildings. 34, 6, 581-591.

ISO 7933 2004. Ergonomics of the thermal environment. Analytical determination and interpretation of heat stress using calculations of the predicted heat strain. ISO, Geneva.

Kuno, S. 1995. Comfort and Pleasantness. Nagoya, Japan: Pan-Pacific Symposium on Building and Urban Environmental Conditioning in Asia, pp. 383-392.

Lee, J.Y., Nakao, K., Tochihara, Y. 2011. Validity of perceived skin wettedness mapping to evaluate heat strain. Eur. J. App. Physiol. 111, 10, 2581-2591.

Machado-Moreira, C.A., Wilmink, F,, Meijer, A., Mekjavic, I.B., Taylor, N.A. 2008 Local differences in sweat secretion from the head during rest and exercise in the heat. Eur. J. App. Physiol, $104,257-264$.

Machado-Moreira, C.A., Edkins, E., Iabushita, A.S., Maruca, P., Taylor, N.A.S. 2009. Sweat gland recruitment following thermal and psychological stimuli. X111 International Conference of Environmental Ergonomics, Boston, p. 478

Nadel, E.R., Stolwijk, J.A. 1973. Effect of skin wettedness on sweat gland response. J. App. Physiol. $35,5,689-694$. 
Nadel, E.R., Bullard, R.W., Stolwijk, J.A. 1971. Importance of skin temperature in the regulation of sweating. J. App. Physiol. 31, 1, 80-87.

Nishi, Y., Gagge, A.P. 1977. Effective temperature scale useful for hypo- and hyperbaric environments. Aviat. Space Environ. Med. 48, 2, 97-107.

Smith, C.J., Havenith, G. 2011. Body mapping of sweating patterns in male athletes in mild exerciseinduced hyperthermia. Eur. J. App. Physiol, 111, 7, 1391-1401.

Smith, C.J., Havenith, G. 2012. Body mapping of sweating patterns in athletes: A sex comparison. Med. Sci. Sports Exerc. 44, 12, 2350-2361.

Thomas, P.E., Korr, I.M. 1957. Relationship between sweat gland activity and electrical resistance of the skin. J. App. Physiol. 10, 3, 505-510.

Umbach, K.H. 1982. Effect if local heat and moisture build-up on wear comfort of clothing. Hohensteiner Forschungsbericht, Clothing Physiol. 1-10.

Wilder, J. 1962. Basimetric approach (law of initial value) to biological rhythms. Ann. NY Acad. Sci. 98, 4, 1211-1220.

Winslow, C.E.A., Herrington, L.P., Gagge, A.P. 1939. Physiological reactions and sensations of pleasantness under varying atmospheric conditions. ASHVE, 44, 179-194. 

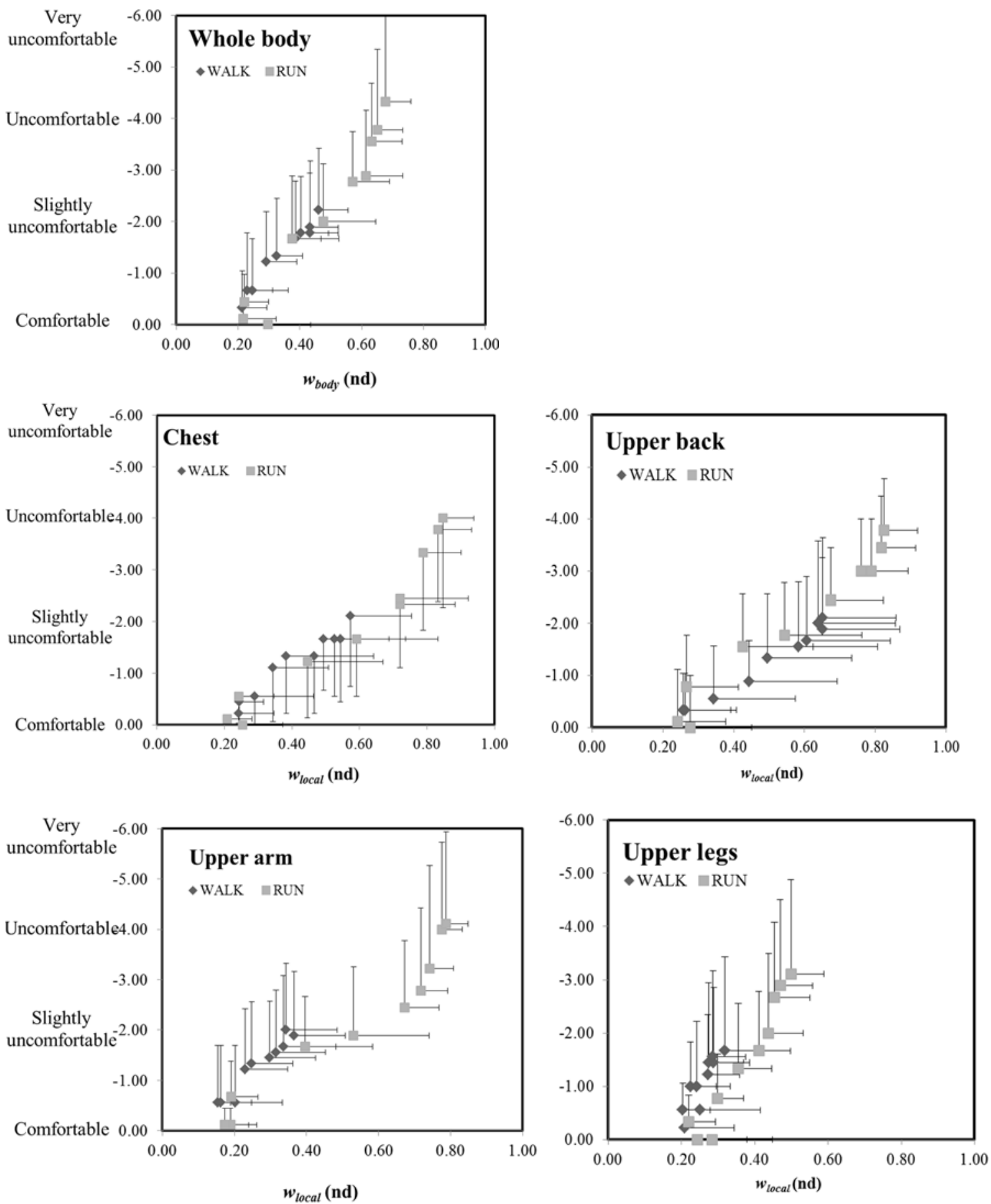

Fig 1: The relationship between local thermal comfort and $w_{\text {local }}$ in both conditions (WALK and RUN), for the whole body and each location. Graphs based on untransformed data. 

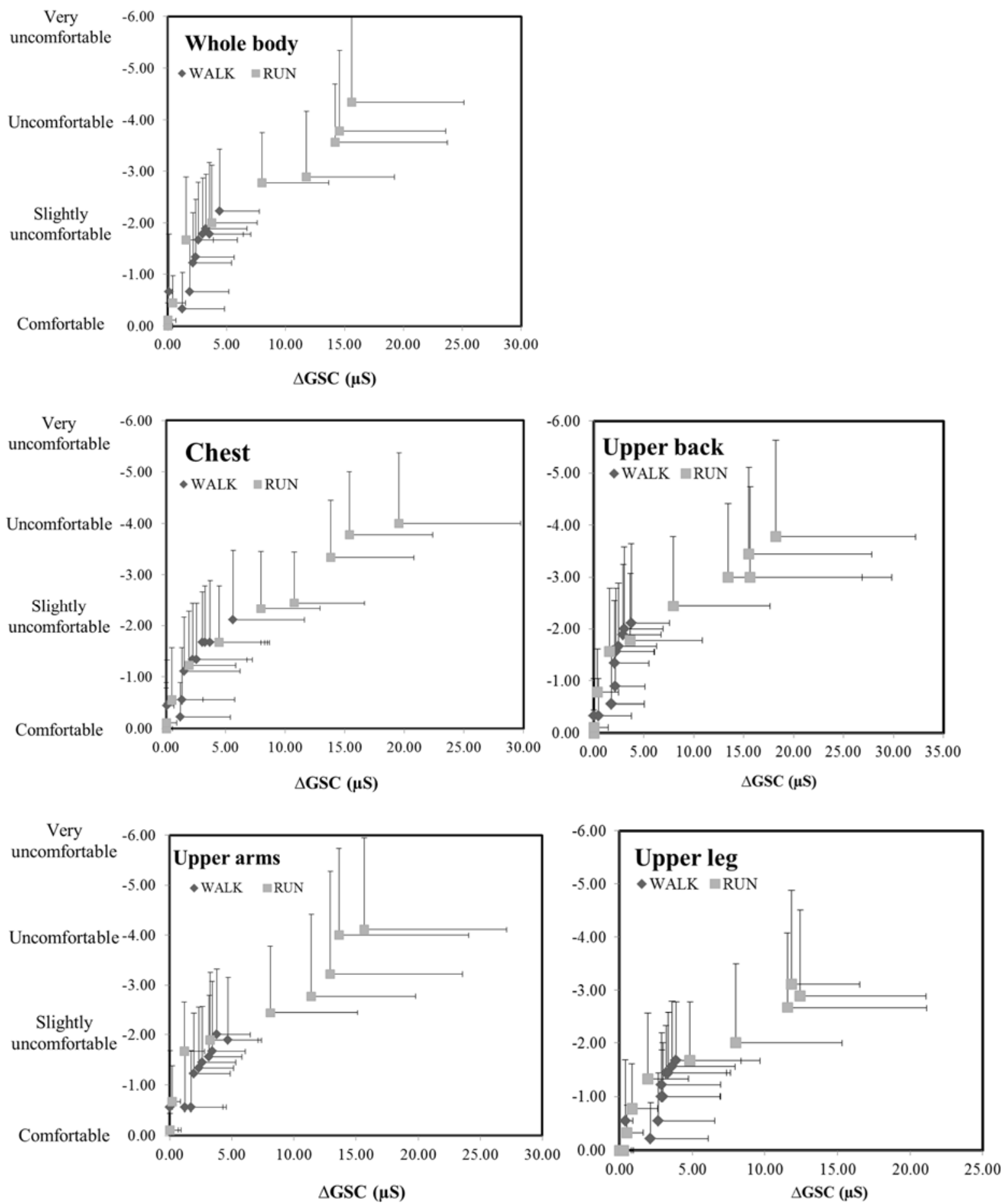

Fig 2: The relationship between local thermal comfort and $\triangle \mathrm{GSC}$ in both conditions (WALK and RUN), for the whole body and at each location. Graphs based on untransformed data. 
Table 1: The mean values ( $\pm \mathrm{SD}$ ) of $w_{\text {local }}, \Delta \mathrm{GSC}$ and $T_{s k}$ during the WALK and RUN. Significant differences between WALK and RUN during rest is denoted by * $(\mathrm{p}<0.05)$ and $* *(\mathrm{p}<0.001)$ (without corrections) and by $\$ \$ p<0.005$ (with Bonferroni adjustments).

\begin{tabular}{|c|c|c|c|c|c|c|}
\hline & \multicolumn{3}{|c|}{ Walk } & \multicolumn{3}{|c|}{ RUN } \\
\hline & $w_{l o c a l}(\mathrm{nd})$ & $\begin{array}{l}\Delta \mathrm{GSC} \\
(\mu \mathrm{S})\end{array}$ & $T_{s k}\left({ }^{\circ} \mathrm{C}\right)$ & $w_{\text {local }}(\mathrm{nd})$ & $\Delta \mathrm{GSC}(\mu \mathrm{S})$ & $T_{s k}\left({ }^{\circ} \mathrm{C}\right)$ \\
\hline Whole body & $0.46 \pm 0.09$ & $4.4 \pm 3.4$ & $33.4 \pm 0.37$ & $0.68 \pm 0.08^{* * \$ \$}$ & $15.6 \pm 9.5^{*}$ & $33.4 \pm 0.57^{* *}$ \\
\hline Chest & $0.57 \pm 0.18$ & $5.6 \pm 6.0$ & $33.7 \pm 0.72$ & $0.85 \pm 0.09^{* \$}$ & $19.6 \pm 0.2^{*}$ & $35.2 \pm 1.4$ \\
\hline Upper back & $0.65 \pm 0.21$ & $3.7 \pm 3.8$ & $33.9 \pm 0.87$ & $0.83 \pm 0.09^{* \$}$ & $18.2 \pm 14.0^{*}$ & $33.8 \pm 1.18$ \\
\hline Upper arms & $0.37 \pm 0.14$ & $4.7 \pm 2.7$ & $33.4 \pm 1.14$ & $0.79 \pm 0.06^{* * \$ \$}$ & $15.7 \pm 1.5^{*}$ & $34.5 \pm 1.49$ \\
\hline Upper legs & $0.32 \pm 0.03$ & $3.8 \pm 4.5$ & $33.3 \pm 0.89$ & $0.50 \pm 0.09^{* * \$ \$}$ & $11.8 \pm 4.7^{*}$ & $32.4 \pm 1.44$ \\
\hline
\end{tabular}


Table 2: Regression coefficients for the prediction of whole body and local thermal comfort. The strength of the relationship ( $\left.\mathrm{r}^{2}\right)$ between thermal comfort and each predictor $\left({ }^{*} \mathrm{p}<0.05,{ }^{* *} \mathrm{p}<0.001\right) . \dagger$ Indicates where data was transformed using exponential function $\left.\left(\mathrm{Y}=\mathrm{a}+\mathrm{b} \cdot e^{x}\right)\right]$ to produce approximate linear relations prior to correlation analysis, $\dagger \dagger$ indicates where data was transformed using a square root function $(\mathrm{Y}=\mathrm{a}+\mathrm{b} \cdot \sqrt{X}]$ to produce approximate linear relations prior to correlation analysis.

\begin{tabular}{|c|c|c|c|c|c|c|c|}
\hline & \multirow[b]{2}{*}{ Parameter } & \multicolumn{3}{|c|}{ WALK } & & \multicolumn{2}{|c|}{ RUN } \\
\hline & & $\mathrm{a}$ & $\mathrm{b}$ & $\mathrm{r}^{2}$ & $\mathrm{a}$ & $\mathrm{b}$ & $r^{2}$ \\
\hline \multirow[t]{4}{*}{ Whole body } & $w_{\text {body }}$ & -6.5964 & 0.9011 & $0.96 * *$ & -5.3683 & 6.585 & $0.95+* *$ \\
\hline & $\Delta \mathrm{GSC}$ & -1.9989 & 1.8099 & $0.92 \uparrow \uparrow * *$ & -0.984 & -0.0079 & $0.97 \dagger \dagger * *$ \\
\hline & $T_{s k}$ & -1.0151 & 32.022 & $0.75^{*}$ & -2.2029 & 69.823 & $0.94 * *$ \\
\hline & $T_{c}$ & -5.2145 & 191.88 & $0.56^{*}$ & -3.8561 & 142.3 & $0.89 * *$ \\
\hline \multirow[t]{4}{*}{ Chest } & $w_{\text {local }}$ & -4.7525 & 0.7399 & $0.93 * *$ & -3.2952 & 4.0198 & $0.96+* *$ \\
\hline & $\Delta \mathrm{GSC}$ & 0.9556 & -0.1896 & $0.78 \uparrow \uparrow * *$ & -0.9051 & 0.0967 & $0.98 \uparrow \uparrow * *$ \\
\hline & $T_{s k}$ & -0.982 & 31.823 & $0.37^{*}$ & -2.5048 & 84.332 & $0.96 * *$ \\
\hline & $T_{c}$ & -5.1596 & 189.99 & $0.55^{*}$ & -3.6915 & 136.34 & $0.92 * *$ \\
\hline \multirow[t]{4}{*}{ Upper back } & wlocal $_{\text {lo }}$ & -4.3006 & 0.855 & $0.98 * *$ & -3.1824 & 3.740 & $0.96+* *$ \\
\hline & $\Delta \mathrm{GSC}$ & -1.5898 & 0.9911 & $0.78 \uparrow+* *$ & -0.8035 & -0.1734 & $0.97 \dagger+* *$ \\
\hline & $T_{s k}$ & -1.0847 & 35.283 & $0.50^{*}$ & -3.762 & 123.91 & $0.69^{*}$ \\
\hline & $T_{c}$ & -6.1957 & 228.33 & $0.65^{*}$ & -3.2998 & 121.62 & $0.87^{*}$ \\
\hline \multirow[t]{4}{*}{ Upper arm } & $w_{\text {local }}$ & -6.8488 & 0.5382 & $0.92 * *$ & -3.4114 & 3.7919 & $0.95 † * *$ \\
\hline & $\Delta \mathrm{GSC}$ & -0.8114 & 0.0758 & $0.71 \uparrow \uparrow * *$ & -0.9148 & -0.1811 & $0.95 \uparrow \uparrow * *$ \\
\hline & $T_{s k}$ & -0.8686 & 27.362 & $0.75 * *$ & -1.4516 & 45.931 & $0.93 * *$ \\
\hline & $T_{c}$ & -4.7437 & 174.51 & $0.60 * *$ & -3.6463 & 134.49 & $0.90 * *$ \\
\hline \multirow[t]{2}{*}{ Upper leg } & wlocal $_{\text {lol }}$ & -11.583 & 1.9072 & $0.78 * *$ & -7.9312 & 10.021 & $0.94 \uparrow * *$ \\
\hline & $\Delta \mathrm{GSC}$ & -3.061 & 4.227 & $0.91 \uparrow \uparrow * *$ & -0.8735 & 0.1871 & $0.97 \dagger \dagger * *$ \\
\hline
\end{tabular}




\begin{tabular}{|c|c|c|c|c|c|c|c|}
\hline & $T_{s k}$ & -0.6533 & 20.21 & $0.88^{* *}$ & -1.1586 & 35.52 & $0.78^{* *}$ \\
\hline & $T_{c}$ & -4.1404 & 152.37 & $0.58^{* *}$ & -2.9783 & 110.09 & $0.94^{* *}$ \\
\hline
\end{tabular}


Table 3: The mean $( \pm \mathrm{SD})$ thermal comfort limits for each location during WALK and RUN, which corresponds to when locations no longer felt comfortable. No significant differences between WALK and RUN were found.

\begin{tabular}{ccccc}
\hline & \multicolumn{2}{c}{ WALK } & \multicolumn{2}{c}{ RUN } \\
& $w$ & $\Delta \mathrm{GSC}$ & $w$ & $\Delta \mathrm{GSC}$ \\
\hline Whole body & $0.26 \pm 0.11$ & $2.4 \pm 3.7$ & $0.31 \pm 0.21$ & $1.5 \pm 3.7$ \\
Chest & $0.27 \pm 0.10$ & $2.2 \pm 5.9$ & $0.39 \pm 0.32$ & $2.6 \pm 3.5$ \\
Upper back & $0.30 \pm 0.12$ & $1.7 \pm 3.6$ & $0.36 \pm 0.10$ & $1.6 \pm 1.8$ \\
Upper arm & $0.22 \pm 0.11$ & $2.3 \pm 3.6$ & $0.28 \pm 0.22$ & $0.8 \pm 0.7$ \\
Upper leg & $0.22 \pm 0.03$ & $4.4 \pm 4.1$ & $0.22 \pm 0.10$ & $2.0 \pm 1.7$ \\
\hline
\end{tabular}

Table 4: The maximum discomfort score at the end of each test and the corresponding $w_{\text {local }}$ and $\Delta$ GSC values. Significant differences between WALK and RUN is donated by $*(\mathrm{p}<0.05)$ or $* *(\mathrm{p}<0.001)$.

\begin{tabular}{ccccccc}
\hline & \multicolumn{3}{c}{ WALK } & & \multicolumn{2}{c}{ RUN } \\
\hline & $\begin{array}{c}\text { Discomfort } \\
\text { score }\end{array}$ & $w$ & $\Delta \mathrm{GSC}$ & $\begin{array}{c}\text { Discomfort } \\
\text { score }\end{array}$ & $w$ & $\Delta \mathrm{GSC}$ \\
\hline Whole & $-2.2 \pm 1.2$ & $0.46 \pm 0.09$ & $4.4 \pm 3.4$ & $-4.3 \pm 1.7^{* *}$ & $0.68 \pm 0.08^{* *}$ & $15.6 \pm 9.5^{* *}$ \\
body & & & & & & \\
Chest & $-2.1 \pm 1.4$ & $0.57 \pm 0.19$ & $5.6 \pm 6.0$ & $-4.0 \pm 1.7^{* *}$ & $0.85 \pm 0.09^{* *}$ & $19.6 \pm 10.2^{* *}$ \\
Upper back & $-2.1 \pm 1.5$ & $0.65 \pm 0.21$ & $3.7 \pm 3.8$ & $-3.8 \pm 1.9^{*}$ & $0.83 \pm 0.09^{*}$ & $18.2 \pm 14.0^{*}$ \\
\hline
\end{tabular}




\begin{tabular}{lllllll}
\hline Upper arm & $-1.9 \pm 1.3$ & $0.37 \pm 0.14$ & $4.7 \pm 2.7$ & $-4.1 \pm 1.8^{* *}$ & $0.79 \pm 0.06^{* *}$ & $15.7 \pm 11.5^{*}$ \\
Upper leg & $-1.7 \pm 1.1$ & $0.32 \pm 0.03$ & $3.9 \pm 4.5$ & $-3.1 \pm 1.8^{* *}$ & $0.50 \pm 0.09^{* *}$ & $11.8 \pm 4.7^{* *}$ \\
\hline
\end{tabular}


